\title{
Microstructure and mechanical properties of ZM6 magnesium alloy after continuous variable cross-section direct extrusion
}

\author{
F. $\mathrm{Li}^{1 *}$, W. Shi ${ }^{1}$, Z. L. $\mathrm{Hu}^{2}$, X. Zeng ${ }^{2}$ \\ ${ }^{1}$ School of Materials Science and Engineering, Harbin University of Science and Technology, Harbin 150040, P. R. China \\ ${ }^{2}$ School of Automotive Engineering, Wuhan University of Technology, Wuhan 430070, P. R. China
}

Received 16 February 2014, received in revised form 28 March 2014, accepted 15 May 2014

\begin{abstract}
Due to the shortcomings existing in the methods of the traditional severe plastic deformation for the production of refined grain material, this paper presents a new extrusion method - continuous variable cross-section direct extrusion (CVCDE), with which interim dies between the billet and the die are added. This method not only shortens the process, but also realizes the integration of material preparation-forming technology. Compared with conventional extrusion, the extrusion with interim dies has a greater effect on the grain refinement and improves the tensile strength. At the same time, the fracture mechanism changes from brittle cleavage to ductile fracture. By the use of CVCDE, the metal flow uniformity is significantly improved and the possibility of the surface crack decreases. The streamline fold defects disappear when two interim dies have been employed. It provides a theoretical basis for the technique of short process extrusion forming so as to manufacture high performance magnesium alloy production.
\end{abstract}

K e y words: microstructure, mechanical properties, continuous variable cross-section direct extrusion (CVCDE), magnesium alloy

\section{Introduction}

Magnesium alloy has been favored in the areas of aerospace, transportation and equipment manufacturing, due to a series of excellent features, such as high specific strength and specific stiffness. Compared with casting method [1], plastic processing method can fully refine material microstructure and improve the overall performance of the material [2]. Many of these new materials as well as traditional materials have limited workability. Extrusion is a metalworking process that can be used to deform these difficult materials into the shapes needed for specific applications [3].

Significant improvement in mechanical properties of the alloy can be obtained with increasing extrusion strain [4]. In recent years, the method of the severe plastic deformation has attracted increasing attention to produce fine-grained materials [5], such as equal channel angular pressing (ECAP) [6], accumulative roll bonding (ARB) [7], high pressure torsion (HPT) [8], cyclic extrusion and compression (CEC) [9], etc.
The CEC has two main types of die structure, which are J. W. Yeh type $[10,11]$ and M. Richert type [12]. The advantage of the former integral type mold is that the mold cavity is separated from the die, and it is easy to replace the die and make comparison experiments with different extrusion ratios. But the container and the die are difficult to maintain coaxial position. The mold structure of the latter modular type is more easily processed and the coaxiality is better than that of the former type. But due to the split structure of the die, the material is prone to emerge leakage and produce defects on the parting surface when the extrusion load is large or extrusion temperature is high.

Lin et al. [13] studied the strain distribution of the ZK60 during CEC by finite element analysis. The results showed that the strain distribution was inhomogeneous after CEC. The strain at the two ends of the sample was lower than that in the middle of the sample. The processing conditions showed a great influence on the strain distribution of the samples. The friction between the billet and the mold was adverse to 


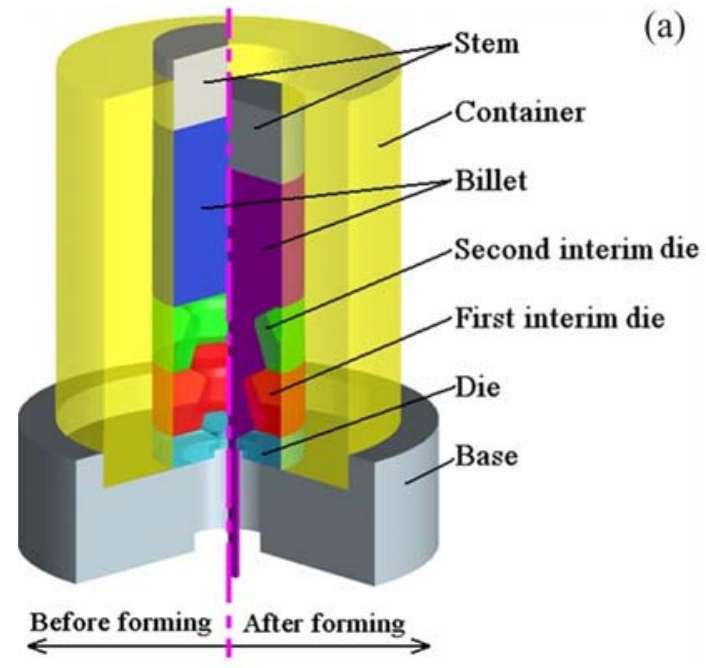

(a)

(b)

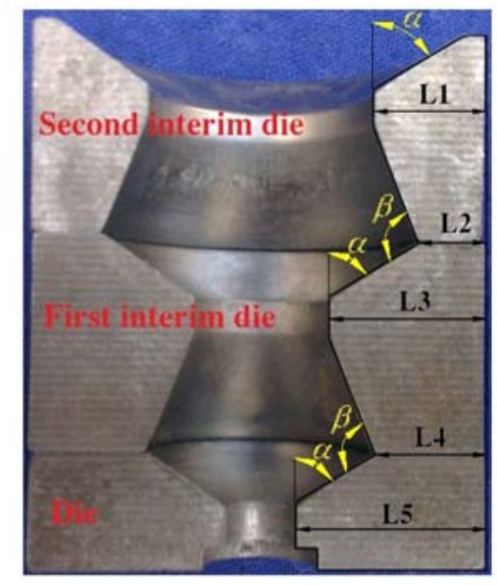

Fig. 1. Schematic of CVCDE: (a) schematic of the forming equipment, (b) structure of the die and interim dies.

the uniformity of the strain distribution. To improve the uniformity of the strain distribution, larger transition radius and lower extrusion angle were chosen.

N. Pardis et al. [14] presented a new method of severe plastic deformation - CEE. This method needed no external back-pressure system, which is the main advantage compared to CEC. N. Pardis studied 1050 aluminum alloy by finite element analysis. The results showed that CEE can make alloy to produce large strain, and have a homogeneous hardness distribution in the sample's cross section.

In conclusion, the above mentioned methods are able to refine the material grain size in certain conditions. However, all of them have some shortcomings due to the process characteristics. Therefore, this paper presents a method named CVCDE, which can be used to refine grain size of materials. In this paper, cast magnesium alloy ZM6 is adopted to study the metal flow behavior and microstructure in the continuous variable cross-section channel.

\section{Theory of CVCDE}

\subsection{Process principle}

CVCDE is the method by which some interim dies between the billet and the die are added. So a channel with continuous variable cross-section is composed by the interim dies and the container. The plastic deformation of the billet occurs when the load is applied by the stem, and is formed by the die after flowing through the multiple interim dies, as shown in Fig. 1.

The billet experiences continuous severe deformation as flows through the channel with continuous variable cross-section during the extrusion forming process (Fig. 1a). This process is similar to the effect of "upsetting-stretching-upsetting". The interim die structure (the size and angle) shows great influence on the local deformation of the billet during the extrusion process. In the study, the half cone angle $\alpha$ of the die and the interim die was $60^{\circ}$ and the intersection angle $\beta$ between the interim dies was $110^{\circ}$, as shown in Fig. 1b. The lengths of $L_{1}-L_{5}$ were variable, which were $10,6,14,10$ and $17 \mathrm{~mm}$, respectively.

According to theoretical analysis, if the number of the interim dies was overmuch, the extrusion deformation in each interim die decreased obviously, and the residual materials in the cavity after forming increased significantly with increasing the overall size of the channel. Generally speaking, the appropriate amount of the interim dies was between 1 and 4 . The amount of interim dies can be adjusted according to the requirement of the grain refining degree.

\subsection{Research scheme}

The aircraft heat-resistant magnesium alloy ZM6 was employed, and the chemical components are shown in Table 1.

The original size of the cylindrical billet was $\varnothing 40 \times 50 \mathrm{~mm}^{2}$, and the product diameter was $\varnothing 6 \mathrm{~mm}$. The extrusion ratio was 44.4. The extrusion temperature and the extrusion speed were $450^{\circ} \mathrm{C}$ and $1 \mathrm{~mm} \mathrm{~s}^{-1}$, respectively.

It was known that the amount of interim dies showed significant effect on the local deformation of each part and the microstructure of the billet. Therefore, the experiments of the ordinary extrusion and CVCDE with one interim die and two interim dies were conducted.

The tensile tests were performed at a crosshead speed of $3 \mathrm{~mm} \mathrm{~min}^{-1}$ using the $100 \mathrm{kN}$ CSS-44300 universal test device, and the samples were machined from typical locations of the extrusion products as shown in Fig. 2. The cross sections were polished 
Ta ble 1. Chemical composition of ZM6

\begin{tabular}{lccccccc}
\hline Element & $\mathrm{Zn}$ & $\mathrm{Zr}$ & $\mathrm{Nd}$ & $\mathrm{Cu}$ & $\mathrm{Ni}$ & impurity & $\mathrm{Mg}$ \\
\hline Content (wt.\%) & $0.2-0.7$ & $0.4-1.0$ & $2.0-2.8$ & $\leq 0.10$ & $\leq 0.01$ & $\leq 0.30$ & margin. \\
\hline
\end{tabular}

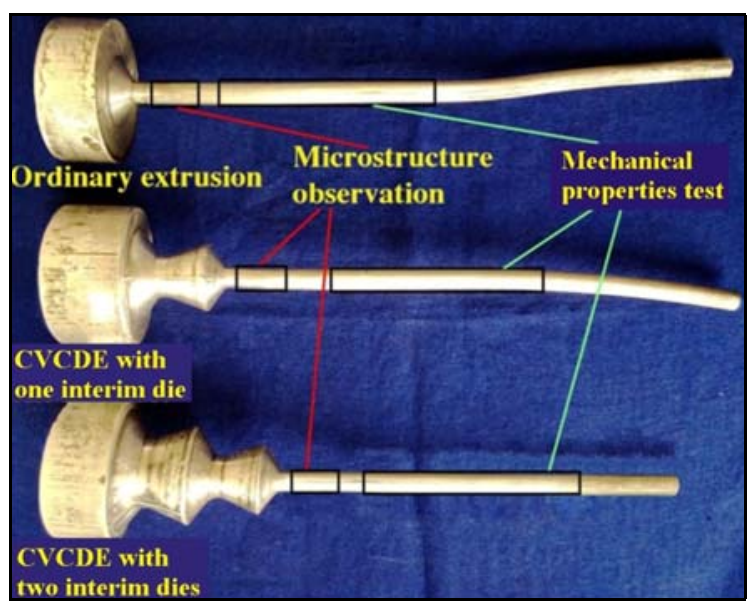

Fig. 2. Experimental results under different extrusion conditions and sample positions.

to a mirror finish and were etched with reagent $(1 \mathrm{ml}$ acetic acid, $1 \mathrm{ml}$ concentrated nitric acid, $1 \mathrm{~g}$ oxalic acid, $150 \mathrm{ml} \mathrm{H}_{2} \mathrm{O}$ ), and then were observed under OLYMPUS-GX71-6230A metallurgical microscope. The tensile fracture morphology was observed by an S-570/HITACHI-4700 scanning electron microscope (SEM).

\section{Results and analysis}

\subsection{Microstructure}

Figure 2 shows the experiment results under different extrusion conditions. As can be seen from Fig. 2, the cavities of the interim dies are fully filled with the metal during the extrusion process. After the metal is extruded from the mold, the microstructure observation and mechanical properties test are carried out.

Figure 3 shows the microstructure of the samples which are taken from the original billet, the products obtained by ordinary extrusion and CVCDE, respectively.

As can be observed, the microstructures of the samples extruded under different conditions consist of equiaxed grains, implying the dynamic recrystallization has occurred when the material is extruded. The grain of the samples produced by ordinary extrusion is coarser than the one which experienced CVCDE. And the grain of the samples extruded with two interim dies is smaller than that extruded with one interim die. At the same time, the refining degree of grains between the ordinary extrusion and CVCDE is different as shown in Fig. 3. The grain distribution of the original magnesium alloy ZM6 billet is very coarse and is extremely irregular. The grain boundary is relatively long and straight (Fig. 3a). After ordinary extrusion, the grain size becomes smaller, and the grain distribution is more uniform. Furthermore, the grain boundary is significantly shorter, as shown in Fig. 3b. The grain size of the sample extruded with one interim die is further decreasing (Fig. 3c). The grain size of the sample extruded with two interim dies continuously reduces and gets more uniform. Besides, the grain boundary becomes more tortuous with the grain refinement conducted as shown in Fig. 3d. The average grain sizes of the samples under different extrusion conditions are measured, as shown in Fig. 3e. The average grain size of the original billet is $50 \mu \mathrm{m}$ and it decreases to $15 \mu \mathrm{m}$ after ordinary extrusion. It is shown that extrusion processing can refine a cast structure. In contrast to ordinary extrusion, the average grain size of CVCDE with one interim die and two interim dies decreases by 13.33 and $46.67 \%$, respectively.

Based on the above analysis, the addition of the interim dies between the die and the billet can improve the effect of the grain refinement of ZM6 magnesium alloy. It is mainly because the addition of the interim die can significantly increase the extrusion strain, thus more energy is provided and the degree of dynamic recrystallization is greater.

\subsection{Tensile properties}

Figure 4 shows the room temperature tensile properties of the samples under different conditions.

It can be seen that the tensile strength of the sample after ordinary extrusion increases from 138 to $225 \mathrm{MPa}$ and the elongation increases from 7.1 to $16.0 \%$, as shown in Fig. 4. When CVCDE with one interim die and two interim dies are conducted, the tensile strengths of the samples are raised by 8.89 and $11.11 \%$, respectively. And the corresponding elongations of the samples are 19.2 and $19.9 \%$, which show a little increase compared to those of the ordinary extrusion samples. The extrusion with an interim die can refine and homogenize the grain. The crack is hard to extend during the tension, and more energy can be absorbed by the grain in the fracture process, thus the strength of the samples is improved greatly. 

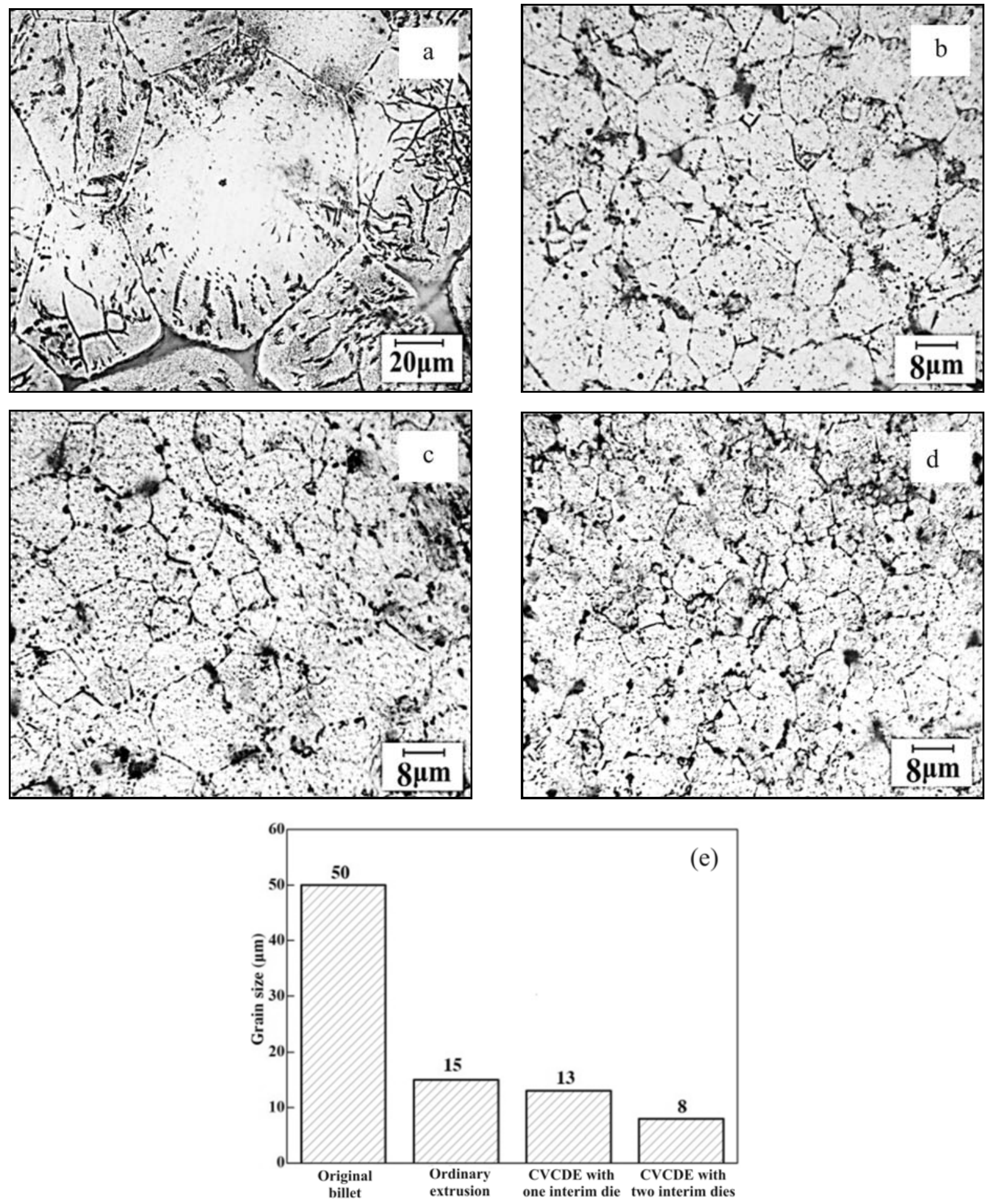

Fig. 3. Microstructure of the samples extruded under different conditions: (a) original billet, (b) after ordinary extrusion, (c) after CVCDE with one interim die, (d) after CVCDE with two interim dies, (e) the average grain sizes of the samples.

\subsection{Fracture morphology}

Figure 5 shows the fracture morphology of the tensile samples under different conditions.

The scanning electron microscope (SEM) images of the fracture surfaces of tensile samples are shown in
Fig. 5. There is no dimple and the crack movement on the fracture surface in Fig. 5a. It shows torn edges and some river features, which is a typical cleavage fracture. The fracture morphology after extrusion deformation is different from the former one. There are lots of dimples at the fracture surface and the main frac- 
ture mechanism is ductile fracture as shown in Fig. 5b. The fracture surface is very smooth. The size of the dimples is very small and the depth is shallow. The distribution of the dimples is very regular. The fracture morphologies of the samples extruded with the interim die are obviously different from those produced by an ordinary extrusion. The size of the dimples becomes large and the depth increases when the billet is extruded with one interim die (Fig. 5c). The fracture morphology of the sample extruded with two interim dies is shown in Fig. 5d. The undulation on the fracture surface also significantly increases and torn edges can be observed. The sample under such condition requires more energy to get fractured. Therefore, using an interim die can delay the production of fracture and improves mechanical properties of the material.

\subsection{The axial stress distribution}

Due to the friction, the stress states of the radial points at the die orifice are different. The axial stress of

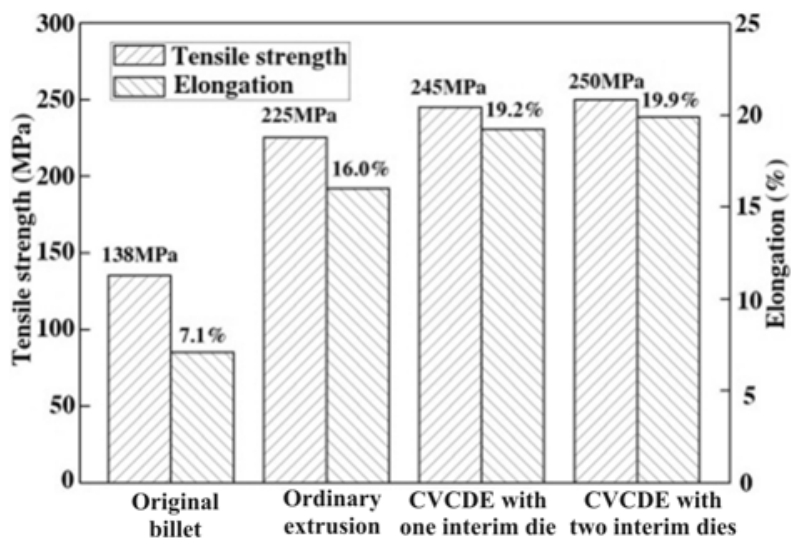

Fig. 4. Mechanical properties under different conditions.

the point at the center is compression stress, while the one near the inside wall of the die is tensile stress. The differences in stress state at the two sides make the metal to flow inhomogeneously, which always causes
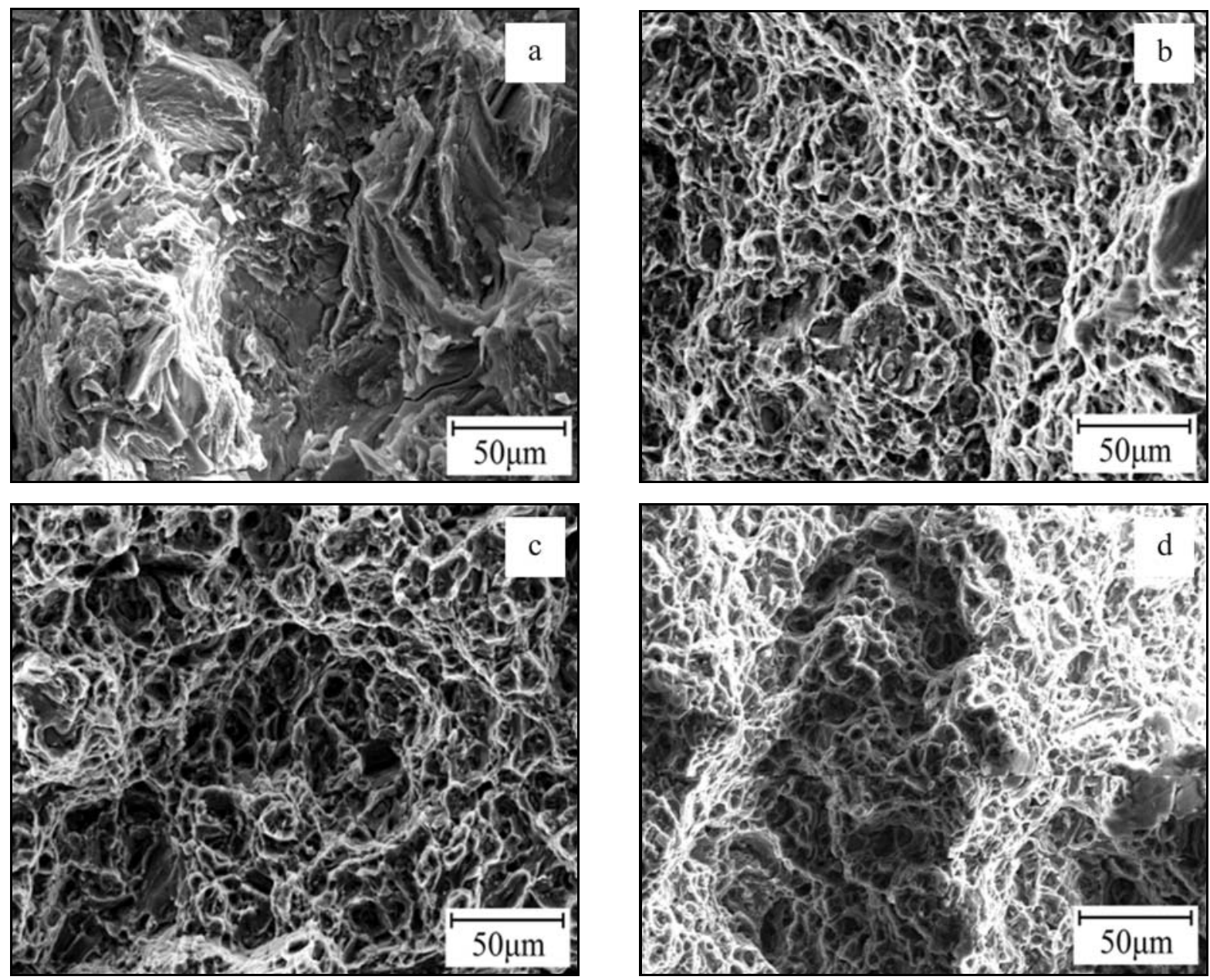

Fig. 5. The fracture morphology of the tensile samples under different conditions: (a) original billet, (b) after ordinary extrusion, (c) after CVCDE with one interim die, (d) after CVCDE with two interim dies. 


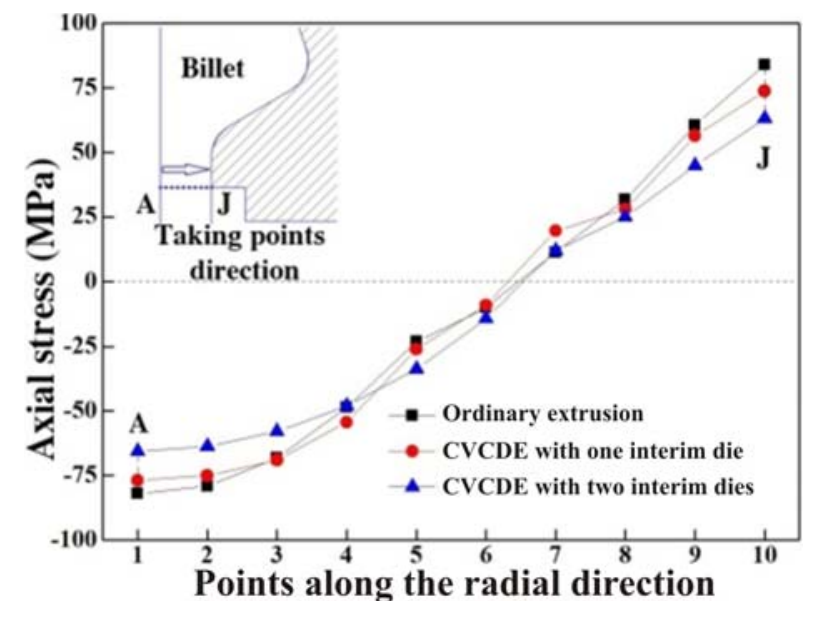

Fig. 6. The distribution of axial stress at the die orifice.

cracks when the tensile stress on the product surface achieves the fracture strength of the metal. Therefore, a finite element simulation software, DEFORM-2D, was used to simulate the process. When the stroke of the stem is $20 \mathrm{~mm}$, the axial stress of the points $(10$ equidistant points from the center to the edge along the radial direction at the die orifice were taken) under different conditions is shown in Fig. 6.

The axial stress from the center to the surface of the product at the die orifice increases gradually. Under ordinary extrusion, the additional stress at the center and the surface of the product is 82 and 83.9 $\mathrm{MPa}$, respectively. The additional stress varies significantly with the addition of interim dies during the extrusion process. When the extrusion processes are adopted with one interim die and two interim dies, the axial stress at the center and the surface of the product decreases by 12 and $25 \%$, respectively. As compared with that under the ordinary extrusion, the difference in the axial stress decreases by 9 and $23 \%$ for the center and surface of the sample. It is indicated that the axial stress difference can be reduced significantly and the distribution of the stress is more uniform by adopting interim die during the extrusion. The appropriate addition of interim die can decrease surface axial stress and avoid the emerging of cracks.

\subsection{Flow uniformity}

The material flow velocity at the die orifice shows an important influence on the twisting and bending of the extruded part. The mean square velocity is used as the objective function to evaluate the material flow velocity during extrusion [15]. The mean square velocity $S$ is defined in Eq. (1). Substituting the axial flow velocity of the equidistant points into the following equation, the values of the mean square velocities are shown in Fig. 6 and the locations of the points are

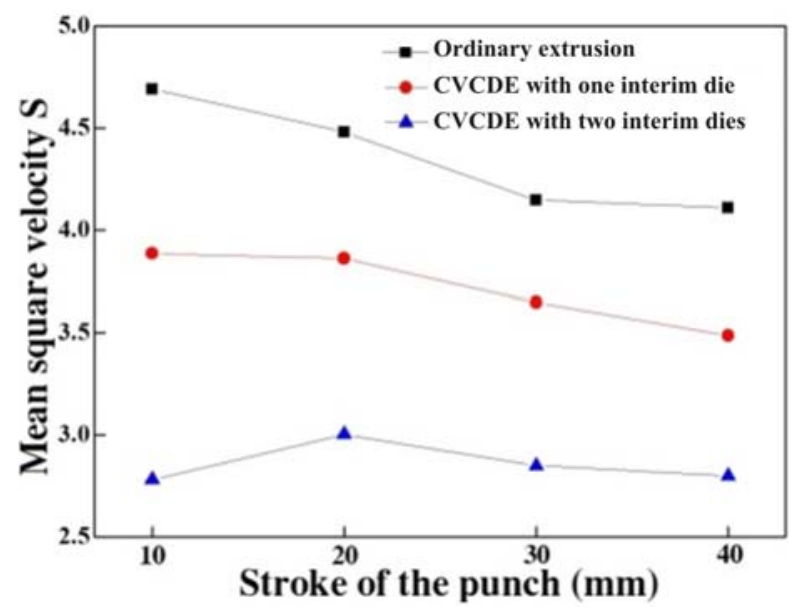

Fig. 7. Comparison of the mean square velocity $S$.

shown in Fig. 7:

$$
S=\sqrt{\frac{\sum_{i=1}^{N}\left(V_{z, i}-V_{z, \mathrm{av}}\right)^{2}}{N}},
$$

where $N$ is the amount of the points, $V_{z, i}$ is the axial velocity of the points and $V_{z \text {,av }}$ is the average axial velocity of the points.

It can be seen that the mean square velocities of the ordinary extrusion and CVCDE with one interim die are gradually decreasing with increasing the stem stroke, as shown in Fig. 7. The mean square velocities of the CVCDE with two interim dies increase before the stem stroke reaches $20 \mathrm{~mm}$, and then decrease. When the stem stroke is $40 \mathrm{~mm}$, namely, reaching the stable extrusion stage, the mean square velocity for the CVCDE with one interim die and the CVCDE with two interim dies is reduced by 15.1 and $31.8 \%$ compared with the ordinary extrusion. It is indicated that the material flow uniformity at the die orifice is improved greatly. Therefore, the possibility of twisting defects is almost eliminated.

As a matter of fact, understanding of how the material close to the billet surface flows and how the flow of the billet surface layer is influenced by extrusion parameters is of great importance [16].

The streamline distribution of the original billet and the samples extruded under different conditions is shown in Fig. 8.

The streamline of the ordinary extrusion sample becomes more curved at the die orifice, and finally it forms folding defects. The streamline distribution of the CVCDE with one interim die becomes relatively uniform at the die orifice, but the extruded product still remains as the unexpanded streamline folding defect. The streamline distribution of the CVCDE with two interim dies is the most uniform. There is still a 


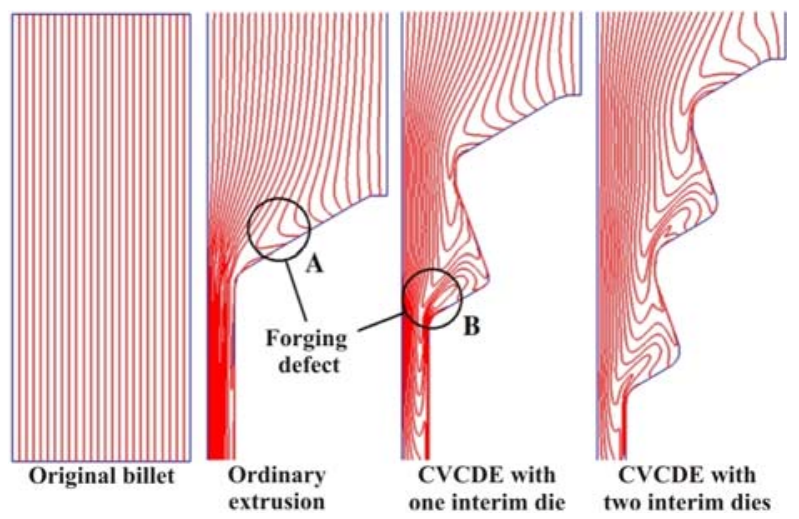

Fig. 8. The streamline distribution.

slight bending trend of the streamline in the channel, but the curved streamline is gradually pulled straight along the axial direction during extrusion. Meanwhile, the streamline at the bottom of the die also bends towards the die orifice. Therefore, the dead zone and folding defects can be completely eliminated in these conditions.

\section{Conclusions}

1. An ordinary extrusion process can effectively refine the grain, and the average grain size is $15 \mu \mathrm{m}$. However, the continuous variable cross-section direct extrusion process shows even more significant grain refinement effect. The average grain sizes of CVCDE with one interim die and two interim dies decrease by 13.33 and $46.67 \%$, respectively. The tensile strengths are correspondingly raised by 8.89 and $11.11 \%$ as compared to ordinary extrusion process.

2 . The fracture morphology of the samples treated with different conditions indicates that under ordinary extrusion, the fracture surface is smooth and the dimples are small and shallow. However, the size of the dimples becomes large and the depth increases after the billet extruded with one interim die. After the billet is dealt with CVCDE with two interim dies, the undulation on the fracture surface significantly increases.

3. The axial tensile stresses on the surface of the samples extruded with one interim die and two interim dies decrease by 12 and $25 \%$, respectively, compared with ordinary extrusion. Due to the addition of interim die, the metal flow uniformity is improved significantly and the cracks are avoided. The folding defects can be completely eliminated by the adoption of CVCDE with two interim dies.

\section{Acknowledgement}

This paper was financially supported by the National Natural Science Foundation of China (No. 51205094). The authors would like to take this opportunity to express their sincere appreciation.

\section{References}

[1] Horynová, M., Zapletal, J., Doležal, P., Gejdoš, P.: Materials and Design, 45, 2013, p. 253. doi:10.1016/j.matdes.2012.08.079

[2] Zhao, Z. D., Chen, Q., Chao, H. Y.: Materials and Design, 31, 2010, p. 1906. doi:10.1016/j.matdes.2009.10.056

[3] Gordon, W. A., Van Tyne, C. J., Moonc, Y. H.: Journal of Materials Processing Technology, 187-188, 2007, p. 662. doi:10.1016/i.jmatprotec.2006.11.158

[4] Chen, Q., Lin, J., Shu, D. Y., Hu, C. K., Zhao, Z. D., Kang, F., Huang, S. H., Yuan, B. G.: Materials Science and Engineering A, 554, 2012, p. 129. doi:10.1016/j.msea.2012.06.025

[5] Westengen, H. K.: Light Materials Age, 58, 2000, p. 44.

[6] Zhao, Z. D., Chen, Q., Chao, H. Y., Hu, C. K., Huang, S. H.: Materials Design, 32, 2011, p. 575. doi:10.1016/j.matdes.2010.08.020

[7] Roohollah, J., Mohammad, R. T., Hossein, E.: Materials Science and Engineering A, 583, 2013, p. 20. doi:10.1016/j.msea.2013.06.068

[8] Mousumi, D., Goutam, D., Mainak, G., Matthias, W., Rajnikant Ghosh, C., Pal, T. K.: Materials Science and Engineering A, 558, 2012, p. 525. doi:10.1016/j.msea.2012.08.040

[9] Pardis, N., Talebanpour, B., Ebrahimi, R., Zomorodian, S.: Materials Science and Engineering A, 528, 2011, p. 7537. doi:10.1016/j.msea.2011.06.059

[10] Lee, S., Yeh, J., Liao, Y. S.: Advanced Engineering Materials, 6, 2004, p. 936. doi:10.1002/adem.200400107

[11] Yeh, J. W., Yuan, S. Y., Peng, C. H.: Materials Science and Engineering A, 252, 1998, p. 212. doi:10.1016/S0921-5093(98)00677-7

[12] Richert, M., Liu, Q., Hansen, N.: Materials Science and Engineering A, 260, 1999, p. 75. doi:10.1016/S0921-5093(98)00988-5

[13] Lin, J. B., Wang, Q. D., Liu, M. P., Chen, Y. J., Hans, J. R.: Transactions of Nonferrous Metal Society of China, 22, 2012, p. 1902. doi:10.1016/S1003-6326(11)61405-2

[14] Pardis, N., Talebanpour, B., Ebrahimi, R., Zommrmdian, S.: Materials Science and Engineering A, 528, 2011, p. 25. doi:10.1016/j.msea.2011.06.059

[15] Yan, H., Wang, G. C., Xia, J. C.: Transactions of Nonferrous Metal Society of China, 14, 2004, p. 890.

[16] Kim, Y. T., Ikeda, K.: Metallurgical and Materials Transactions A, 31, 2000, p. 1635. doi:10.1007/s11661-000-0173-4 